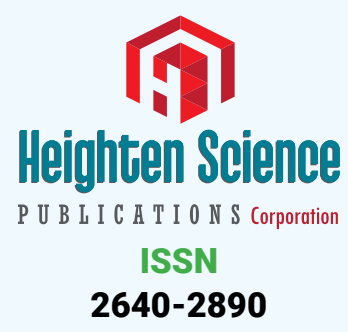

*Address for Correspondence: Ana Ribeiro, Department of Obstetrics and Gynecology, Hospital Center of Baixo Vouga, Rua Dr. Artur Ravara, 3810501 Aveiro, Portugal, Tel: +351911992285; Email: anaribeiro0588@gmail.com

Submitted: 11 March 2019

Approved: 08 May 2019

Published: 09 May 2019

Copyright: (c) 2019 Ribeiro A, et al. This is an open access article distributed under the Creative Commons Attribution License, which permits unrestricted use, distribution, and reproduction in any medium, provided the original work is properly cited

Check for updates
Case Report

\section{Giant cellular angiofibroma of the vulva: case report}

\author{
Ana Ribeiro*, Isabel Ferreira and Filomena Ramos \\ Department of Obstetrics and Gynecology, Hospital Center of Baixo Vouga, Portugal
}

\section{Abstract}

Cellular Angiofibroma is a rare benign mesenchymal tumor without gender preference. It is usually a small $(<3 \mathrm{~cm})$, well-circumscribed, mostly asymptomatic and typically slow growing. Surgical removal of the mass with its capsule is the preferred treatment, not only helps guarantee complete excision and prevent its recurrence but also minimize blood loss. We present the case of a 76-year-old woman with a giant vulvar mass.

\section{Introduction}

Cellular Angiofibroma is a rare benign mesenchymal tumor without gender preference. Nucci et al. first described it in 1997 [1]. It occurs almost exclusively in the superficial soft tissue of the genital area. Although it has preference for the vulvar region, few extravulvar cellular angiofibromas have also been reported. It has limited potential for local recurrence and excision is the treatment of choice [2]. We present the case of a woman with a massive angiofibroma in the right vulvar region.

\section{Case Report}

A 76-year-old female patient presented with a vulvar mass for 10 years, which was progressively increasing in size. The mass was painless. On examination, it was a pediculated tumor of about $7 \times 6 \mathrm{~cm}$ that was solid, arising from the right labia and extending to the vulva. The patient's gynecological examination was normal. She was been in the postmenopausal period for 25 years. MRI revealed an $8,3 \times 4,4 \times 4,5$ lobulated soft tissue mass with origin in the right major labia and exophytic grow.

The patient underwent resection of the mass. The resected mass measured $7 \times 4$, $5 \times 4 \mathrm{~cm}$ and was multilobulated and lipomatous with elastic consistency. Histological examination shows fibroadipose tissue with presence of angiomatoid vascular proliferation with areas of myxoma type. No signs of malignancy. The post operatory was uneventful and there was no recurrence in the follow-up till 12 months (Figures 1-4).

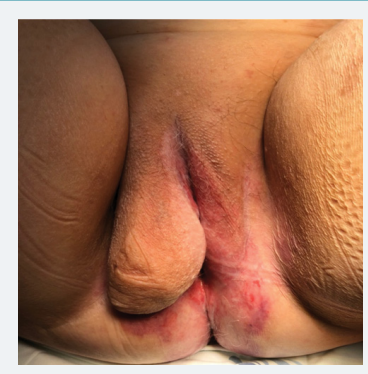

Figure 1: Angiofibroma arising from the right major labia.

How to cite this article: Ribeiro A, Ferreira I, Ramos F. Giant cellular angiofibroma of the vulva: case report. Clin J Obstet Gynecol. 2019; 2: 003-005. https://doi.org/10.29328/journal.cjog.1001016 


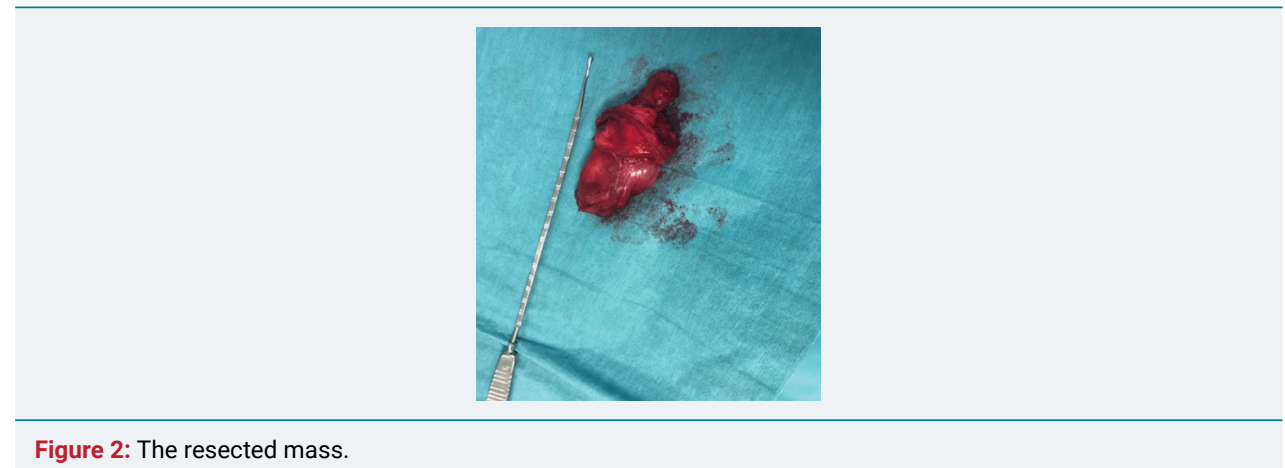

Figure 2: The resected mass

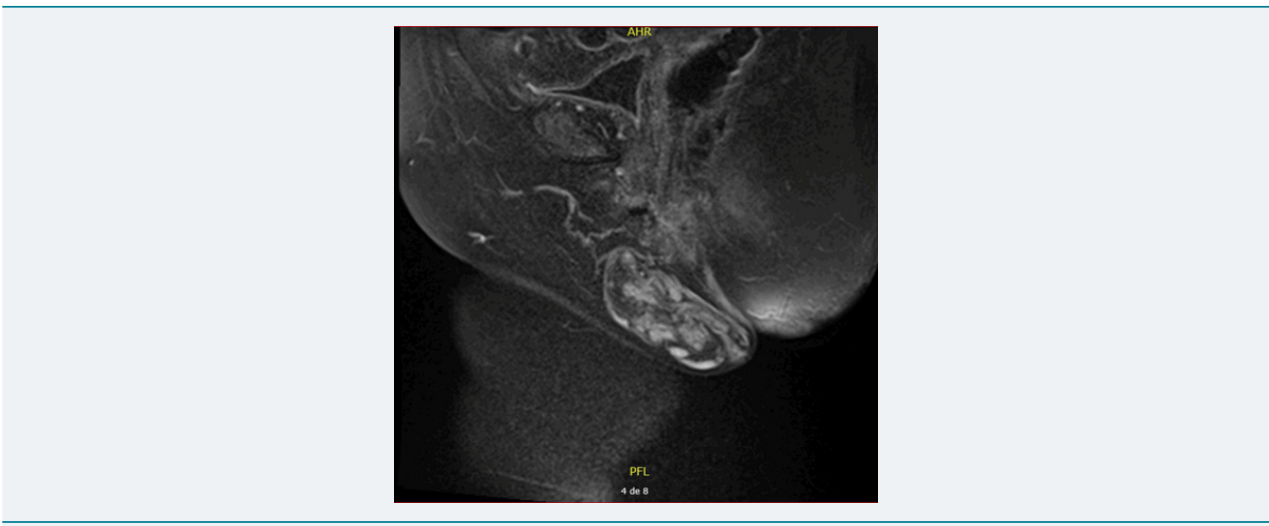

Figure 3: Sagittal view of the pelvis on MRI.

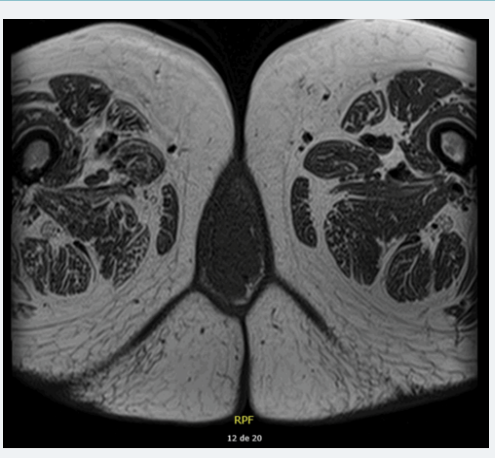

Figure 4: Transverse view of the pelvis on MRI.

\section{Discussion}

A variety of soft tissue tumors occur in the vulvovaginal area of women. Most are small, hormonally responsive, clinically indolent and they are often mistaken for a Bartholin gland cyst [3].

Cellular angiofibroma is a small $(<3 \mathrm{~cm})$, well-circumscribed, mostly asymptomatic, typically slow growing, and benign stromal tumor. It has been diagnosed equally in male and female patients in recent years and most often found in the distal genital region. In women, this tumor usually arises in the subcutaneous tissues of the vulva and is characteristically reported in middleaged women.

In the differential diagnosis, spindle cell lipoma, angiomyofibroblastoma, aggressive angiomyxoma, and smooth muscle tumor must be considered. Immunohistochemical characteristics are useful in the differential diagnosis of soft tissue tumors.

Immunohistochemistry is also useful in indicating atypical and sarcomatous transformation [1]. 
Histologically, cellular angiofibroma has two principle components - fusiform cells and prominent blood vessels. The term cellular angiofibroma was chosen to emphasize the both components. These tumors are almost always positive with estrogen and progesterone receptors, suggesting they probably arise from the hormone receptor positive [4-8].

Diagnosis of soft tissue tumors of the vulva can be challenging and frequently necessitates the use of MRI for further characterization and to aid surgical planning. Cellular angiofibroma are almost always encapsulated, well circumscribed, and hypervascular. Surgical removal of the mass with its capsule not only helps guarantee complete excision and prevent its recurrence but also minimize blood loss [3].

In the reported cases, simple local excision was adequate, and in cases with atypical and sarcomatous transformation, radical excision with negative surgical boundaries is recommended. The surgical removal of these tumors requires thorough knowledge of pelvic anatomy to minimize blood loss. There are no reports of recurrence.

\section{References}

1. Nucci MR, Granter SR, Fletcher CD. Cellular angiofibroma: a benign neoplasm distinct from angiomyofibroblastoma and spindle cell lipoma. Am J Surg Pathol. 1997; 21: 636-644. Ref.: https://tinyurl.com/y5uywugv

2. Lane JE, Walker AN, Mullis EN Jr, Etheridge JG. Cellular angiofibroma of the vulva. Gynecol Oncol. 2001; 81: 326-329. Ref.: https://tinyurl.com/yy5poutv

3. Khmou M, Lamalmi N, Malihy A, et al. Cellular angiofibroma of the vulva: a poorly known entity, a case report and literature review. BMC. Clin Pathol. 2016; 16: 8. Ref.: https://tinyurl.com/y4lwhpug

4. Chen E, Fletcher DM. Cellular angiofibroma with Atypia or sarcomatous transformation: clinicopathologic analysis of 13 cases. American Journal of Surgical Pathology. 2010; 34: 707-714. Ref.: https://tinyurl.com/y3gzdawl

5. Shojaei H, Albertin C, Schaus A, Al-Niaimi A. Painful cellular angiofibroma of the vulva: case report. OA Case Reports. 2013; 2: 91. Ref.: https://tinyurl.com/yy5poutv

6. Upreti S, Morine A, $\mathrm{Ng} \mathrm{D}$, et al. Lipomatous variant of angiomyofibroblastoma: a case report and review of the literature. J Cutan Pathol. 2015; 42: 222-226. Ref.: https://tinyurl.com/y4klasuw

7. Mandato VD, Santagni S, Cavazza A, Aguzzoli L, Abrate M, La Sala GB. Cellular angiofibroma in women: a review of the literature. Diagnostic Pathology. 2015; 10: 114. Ref.: https://tinyurl.com/y3qampl6

8. McCluggage WG, Perenyei M, Irwin ST. Recurrent cellular angiofibroma of the vulva. J Clin Pathol. 2002; 55: 477-479. Ref.: https://tinyurl.com/y2xw4m2j 